\title{
Nursing care for patient in postoperatory heart surgery in the Intensive Care Unit
}

\author{
Cuidados de enfermagem ao paciente no pós-operatório de cirurgia cardíaca, na Unidade de Terapia Intensiva
}

Cuidados de enfermería al paciente en el postoperatorio de cirugía cardíaca, en la Unidad de Cuidados Intensivos

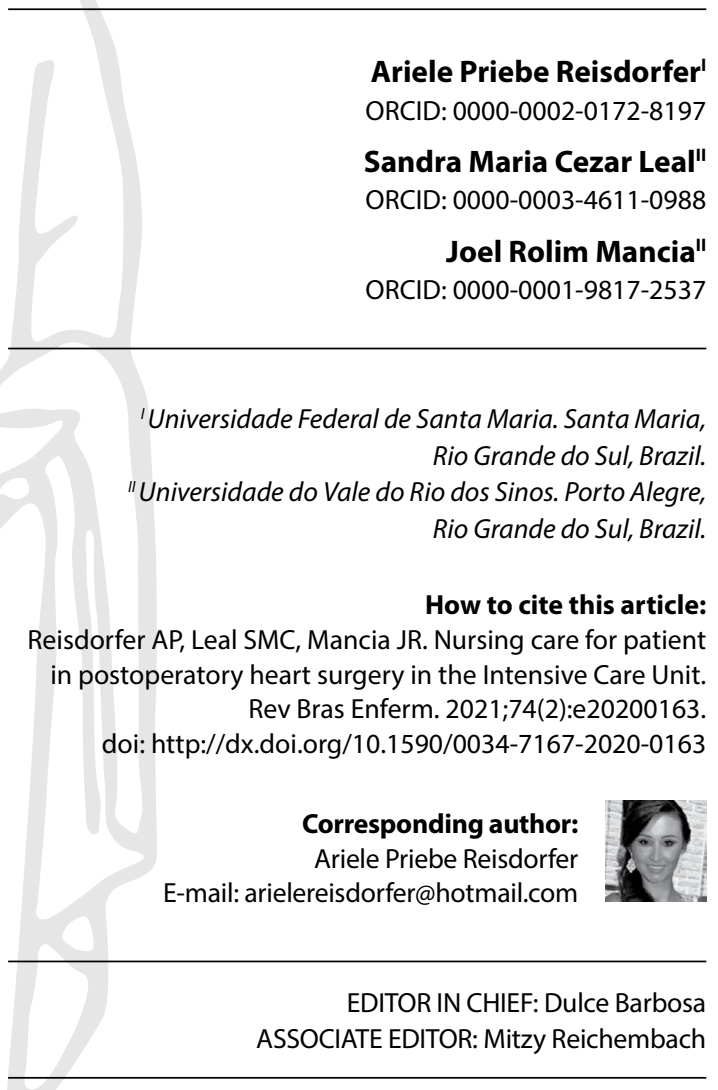

Submission: $03-13-2020$
Approval: 11-01-2020

\section{ABSTRACT}

Objective: To investigate the critical nodes related to nursing care for patients in the postoperative period of cardiac surgery. Methods: Exploratory study with a qualitative approach. Data collected through semi-structured interviews with 27 members of the nursing team working in the Intensive Care Unit. Material submitted to thematic analysis. Results: Three categories emerged: Flaws in the professional qualification for patient care in the postoperative period of cardiac surgery; Team challenges concerning specific patient care in the postoperative period of cardiac surgery; and (dis) organization of work in the Intensive Care Unit and its impact on nursing care for patients in the postoperative period of cardiac surgery. Final considerations: Given the identification of the critical nodes, the professionals presented suggestions to overcome daily difficulties: investments in strategies for Permanent Education in Health; creation of tools to guide patient assistance in the postoperative of cardiac surgery; and provision of adequate human resources.

Descriptors: Nursing Care; Patients; Cardiovascular Surgical Procedures; Intensive Care Units; Patient Safety.

\section{RESUMO}

Objetivo: Investigar os nós críticos relacionados ao cuidado de enfermagem ao paciente no pósoperatório de cirurgia cardíaca. Métodos: Estudo exploratório com abordagem qualitativa. Dados coletados por meio de entrevista semiestruturada com 27 integrantes da equipe de enfermagem, atuantes na Unidade de Terapia Intensiva. Material submetido à análise temática. Resultados: Emergiram três categorias: Fragilidades na qualificação profissional para o cuidado ao paciente no pós-operatório de cirurgia cardíaca; Desafios da equipe em relação aos cuidados específicos ao paciente no pós-operatório de cirurgia cardíaca; e A (des)organização do trabalho na Unidade de Terapia Intensiva e sua repercussão no cuidado de enfermagem ao paciente no pósoperatório de cirurgia cardíaca. Considerações finais: Diante da identificação dos nós críticos, os profissionais apresentaram sugestões para suprir dificuldades cotidianas: investimentos em estratégias de Educação Permanente em Saúde; criação de instrumentos que orientem a assistência ao paciente em pós-operatório de cirurgia cardíaca; e provisão de recursos humanos adequados.

Descritores: Cuidados de Enfermagem; Pacientes; Procedimentos Cirúrgicos Cardiovasculares; Unidades de Terapia Intensiva; Segurança do Paciente.

\section{RESUMEN}

Objetivo: Investigar nudos críticos relacionados al cuidado de enfermería al paciente en postoperatorio de cirugía cardíaca. Métodos: Estudio exploratorio con abordaje cualitativo. Datos recogidos por medio de entrevista semiestructurada con 27 integrantes del equipo de enfermería, actuantes en Unidad de Cuidados Intensivos. Material sometido al análisis temático. Resultados: Emergieron tres categorías: Fragilidades en cualificación profesional para el cuidado al paciente en postoperatorio de cirugía cardíaca; Desafíos del equipo en relación a los cuidados específicos al paciente en postoperatorio de cirugía cardíaca; y La (des) organización del trabajo en Unidad de Cuidados Intensivos y su repercusión en el cuidado de enfermería al paciente en postoperatorio de cirugía cardíaca. Consideraciones finales: Delante la identificación de nudos críticos, los profesionales presentaron sugestiones para suplir dificultades cotidianas: inversiones en estrategias de Educación Permanente en Salud; creación de instrumentos que orienten la asistencia al paciente en postoperatorio de cirugía cardíaca; y provisión de recursos humanos adecuados.

Descriptores: Atención de Enfermería; Pacientes; Procedimientos Quirúrgicos Cardiovasculares; Unidades de Cuidados Intensivos; Seguridad del Paciente. 


\section{INTRODUCTION}

Heart surgery is considered a complex procedure for treating cardiovascular diseases, especially concerning coronary lesions and valvular diseases ${ }^{(1)}$. Myocardial revascularization surgery and valve replacement are the most adopted procedures in these cases: in 2019, about 25.600 surgeries were performed in the country by the Unified Health System (SUS) ${ }^{(2)}$.

The performance of surgeries of this size requires that the immediate postoperative care ( 24 hours after surgery) and part of the mediate (after 24 hours after surgery) be performed in the Intensive Care Unit (ICU), as the intensive care provided in this period is related to the surgical success and adequate patient recovery ${ }^{(3-4)}$. Such assistance requires specific care, such as preserving hemodynamic stability, bleeding monitoring, assessing breathing patterns, recording fluid intake and elimination, and draining flow, among others ${ }^{(5-6)}$. Such care must be taken to prevent neurological, respiratory, cardiovascular, hematological, and infectious complications; and control hypothermia and pain ${ }^{(5)}$.

In this context, the nursing team's work is essential since it performs continuous observation of the patient and needs to make quick decisions, required by the postoperative period of heart surgery ${ }^{(7)}$. These professionals must identify and prevent complications, acting immediately and contributing to reducing hospital stay ${ }^{(5)}$.

The ICU is the sector responsible for providing intensive and specialized care to patients considered clinically severe and aims to reestablish their organism's proper functions ${ }^{(8-9)}$. Given the arsenal of demands in the intensive care environment, specifically regarding care in the postoperative period of heart surgery, it is necessary to consider the qualification of the nursing team that acts in this context and the difficulties they face daily the care for this patient. What can be seen, in practice, are nurses and nursing technicians entering the ICU without the necessary preparation to act in the care of critically ill patients, especially in the postoperative period of heart surgery, since these patients require extreme dedication from the moment they arrive at the unit until discharge ${ }^{(10)}$.

The use of protocols and checklists has been promoted to mitigate flaws in the care process and standardizing care. The implementation and sustainability of such protocols are only possible through a culture change, creating an infrastructure that promotes standardized patient care and feedback mechanisms that verify and balance the care process's leading drivers ${ }^{(11)}$.

In this context, in hospital organizations, a Brazilian study conducted in Paraná sought to understand the difficulties of implementing patient safety strategies in the hospital environment from the nurse managers' perspective. The results pointed out that there was a deficit of professionals' adherence to patient safety strategies. The results also emphasized that "people's engagement for the patient's safety contributes to effective teamwork and co-responsibility among those involved"(12). In many situations is necessary organizational change, which, despite being a challenge, contributes to qualifying the safety of patient care ${ }^{(12)}$.

Given the above and the context of one of the female researchers' care practices, the following research question was conceived: Which critical nodes related to nursing care for patients in the postoperative period of heart surgery?
It is worth mentioning that the concept of "critical nodes" adopted in this study anchors on collective health and strategic planning assumptions, and those nodes are situations that may be resolved by the actors involved in the context of the study ${ }^{(13)}$. So, the study's justification consists of the possibility of the results promoting actions aimed at qualifying patient care in the postoperative period of heart surgery.

\section{OBJECTIVE}

To investigate critical nodes related to nursing care for patients in the postoperative period of heart surgery.

\section{METHODS}

\section{Ethical Aspects}

The study complied with Resolution No. 466/2012 of the National Health Council's ethical precepts. The research project was approved by the Research Ethics Committees of the University of Vale do Rio dos Sinos and the institution where the study was conducted. The professionals were informed about the study's objective, and those who accepted to be part of the research, were asked to sign, in two copies, the Informed Consent Form. Nurses were identified with the letter " $\mathrm{N}$ " and the nursing technicians with the letter " $T$," followed by Arabic numbers to ensure anonymity.

\section{Type of study}

We are conducting an exploratory study with a qualitative approach. The qualitative method was used to study the interactions, beliefs, perceptions, and interpretations of what people experience, think, or feel ${ }^{(14)}$. The study methodology was guided by the COREQ instrument, according to the EQUATOR guidelines.

\section{Methodological procedures}

\section{Study setting}

The survey was conducted in the Adult ICU of a philanthropic reference hospital in the northeastern region of Rio Grande do Sul, which attends $100 \%$ by SUS and has a capacity of 218 beds. The ICU has ten beds for clinical and surgical care of patients over 14 years old.

The hospital staff consists of a nursing team (12 nurses and 23 nursing technicians), critical care physicians and medical clinic residents, physiotherapists, nutritionists, a female speech therapist, and a female pharmacist.

In this institution, as soon as the heart surgery is finished, the patient is transported to the ICU, after the shift of nurses from the Surgical Center (SC) to the ICU. The surgeon and the anesthesiologist accompany the transport, and the patient is admitted to the ICU by the medical and nursing teams in that sector, as well as by the physiotherapist. The nurse is responsible for installing the invasive mean arterial pressure (MAP) and central venous pressure (CVP) systems and for reviewing venous catheters. The nursing technicians are responsible for electrocardiographic monitoring, verification of vital signs, organization of infusion pumps and registering pleural and/or mediastinal drainage output. 


\section{Data source}

The participants were 27 nursing staff professionals ( 9 nurses and 18 nursing technicians) who provide care to the patient in the postoperative heart surgery period, which was selected for convenience and personally invited to be part of the study. The number of participants was defined by data saturation ${ }^{(14)}$. Inclusion criteria were: to be a nurse or a nurse technician provides care for the patient in the heart surgery postoperative period in the ICU under study; and being a nurse who works in the ICU on weekend shifts, time off, during health care nurses sick leave and vacation. The exclusion criteria was professionals who were on sick leave or vacation during the data collection period.

\section{Collection and organization of data}

Data collection was performed by the leading female researcher (female nurse, master's student in a graduate program, with experience in intensive care) through semi-structured interviews in March and April 2016, recorded on audio, upon authorization, and later fully transcribed. These interviews were carried out in a reserved ICU room, according to the participants' convenience and availability, and only the female researcher and the participant were present. The average duration was 12 minutes. This type of interview addresses broad issues and uses a guide to ensure that the study's topics are discussed ${ }^{(15)}$.

The data collection included age, gender, training, work shift, length of work experience, and time in the ICU to identify the participant. For the interview, the researcher followed a script with questions that sought to investigate the critical nodes, that is, the problems and situations that could be resolved by the actors involved in the context under study, related to nursing care for patients in the postoperative period of heart surgery. The questions/guidelines that constituted the script were: "Describe your experiences with patient care in the postoperative period of heart surgery"; "What difficulties can a professional nursing encounter caring for the patient in the postoperative period of heart surgery, when starting activities in the ICU?"; "Which difficulties a nursing professional can find even working longer in the ICU for more time"; and " How do you describe the moment the patient arrives at the ICU after heart surgery?"

\section{Data analysis}

The interviews were fully transcribed, and thematic analysis was used for data treatment ${ }^{(14)}$. This method seeks to discover the core meaning that composes a communication whose presence or frequency means something to the analytical object in question. The thematic analysis has three stages: pre-analysis; exploration of the material; and treatment and interpretation of the results ${ }^{(14)}$.

After data analysis, three categories emerged: Limitations in the professional qualification for patient care in the postoperative period of heart surgery; Team challenges related to specific patient care in the postoperative period of heart surgery; and work (dis)organization in the ICU and its impact on nursing care for patients in the postoperative period of health surgery.

\section{RESULTS}

The average age of the participants was 32 years for nurse technicians and 34 for nurses. The average length of professional experience in the ICU was three years for both categories. Next are presented the three categories that emerged from the data analysis.

\section{Limitations in professional qualification for patient care in the postoperative period of heart surgery}

The deficit of professional qualification, combined with the lack of experience in this work environment, was pointed out by the research participants as one of the main critical nodes to act with the patient in the postoperative period of heart surgery.

Well, experience, experience [...] I don't have yet. (T2)

I guess the biggest critical node is lack of experience. (N3)

Participants reported the need for more significant investment in strategies for Permanent Education in Health (PEH) to overcome this difficulty. One of the main complaints is the institution's shortage of educational practices, especially to new employees.

[...] would have to have more training for new employees [...] I guess the professional has to be more trained to be acting in the care of this patient. ( $\mathrm{T} 1$ )

I think that to take care of cardiac in ICU, we would have to do a training. (N3)

On the other hand, professionals also highlight the need to carry out educational practices with professionals who have been in the service for a more extended time and point out that those interventions should be carried out in their working environment so that everyone can participate.

It's not only because someone has been working there for three years that he doesn't need to recycle himself [...] we know how things work, but it's important to recycle this at all times [...]. (T11)

[...]sometimes you have the skills training, but we have to go down there like everyone else, it's not ok. Only two go over there, and two stay here, [...] if you take some time [...] even when we are here talking, it's much more worthwhile. And when we go, we are forced to go. (T15)

\section{Team challenges concerning specific patient care in the postoperative period of heart surgery}

Due to professional qualification limitations, challenges arise while assisting patients in the postoperative period of heart surgery. In this sense, the participants reported the main critical nodes related to the specific care for this patient: drainage maintenance and handling; administering vasoactive drugs; inserting and measuring invasive MAP and CVP; and recognizing complications in the immediate postoperative period.

Aspects related to the normality of the drainage volume and the pleural and/or mediastinal drains' milking interval were 
mentioned as procedures that generated distress to the participants, especially when they had recently joined the ICU.

[...] What do / have to take care of bleeding [in the drain]? How much bleeding can l accept without always having to tell the doctor?(N2)

Ah, you have to milk the drain. How soon? Ah, you "watch" there. Yeah, but I never stayed [...]. So, how do you "observe" it? (T12)

As for the infusion of vasoactive drugs, participants pointed out the need for more knowledge on the recommendation for this class of drugs.

Actually, it's a lot of medication [...] as I was from another sector, coming here changes everything. Vasodilator, there are some drugsl don't know, you see? (T5)

The issue with drugs too, right? Because sometimes the patient comes and there is a drug that, sometimes, you don't know. (T7)

The patient in the postoperative period of heart surgery needs invasive hemodynamic monitoring. In this sense, the insertion and measurement of invasive MAP and CVP are also critical nodes experienced by some professionals.

\section{[...] regarding MAP and CVP, I didn't remember much [...]. (N9) \\ [...] CVP, which I always hindered when measuring [...] until today. It's simple, but it's complicated. (T5)}

Regarding complications in the immediate postoperative period, the participants recognize the possibility of intercurrences and feel that they have responsibility for detecting signs of complications. In this perspective, they report the need to be prepared to act correctly in the face of complications to ensure safety in patient care.

\section{[...] the heart patient is very, very quick to decompensate. (N8)}

[...] we are never free of any intercurrence, but from the moment we are more prepared, more organized to receive this patient, I believe that things flow more easily, even with intercurrence. (T11)

\section{The (dis)organization in the ICU work and its impact on nursing care for patients in the postoperative period of heart surgery}

It was identified limitations related to nursing care systematization, such as the patient's admission flowchart associated with the complexity of care and the professionals responsible for its execution, the shift transition from CC to ICU, and the nursing's inadequate sizing team.

The moment of patient's admission is defined, by most participants, as tense and confusing, which may harm the work organization to admit him/her to the ICU safely.

It is a tense moment, [...] hectic rush, a lot of tension. (T2)

[...] It seems to me that everybody stays like a bunch of goofy people, [...] it's true [...] everybody stays, [...] 200 people enter [in the ICU box where the patient is admitted] [...]. It's a critical patient, so / will do this, this and this, understand? [...] it's terrifying [...]. (N3)
For the admission of this patient to the ICU to happen appropriately, the nursing technicians reported the need for standardization of actions to improve the care to be provided.

[...] something that instructs [...], when the patient arrives, we have to do such thing. (T3)

[...] a manual, I don't know, what are the main drugs, the main cautions, the main signs of what could happen [...]. So, ah, you have something like this, a folder that has: what is "NORA", [...] nitroglycerin, in the drains, what has to be taken care of. (T1)

Participants, especially nursing technicians, also mentioned difficulties in the division of tasks to determine the action that each team member must perform. With the need to define the responsibility of activities, the apprehension arises with the excess of professionals to admit the patient, causing duplication of actions and damages to the assistance to the other patients admitted to the ICU.

So, I think: one does the HGT, another monitors [...] connects on the respirator, checks heart pressure [...]. (T6)

[...] maximum number of people in the box, because when you look, everyone is inside the box and nobody is circulating in the ICU. [...] it would be interesting to create a routine of what each one does, to delimit how many people are inside the box [...]. (T11)

Participants also reported limitations in the process of shift change between the CC and the ICU since essential aspects for those who will take care of in the ICU are not informed.

[...] they don't pass the intercurrences to you. They never know what surgery he had [...] if he had coronary artery bypass grafting, they don't tell you the bypass that was made [...]. I like to know, I think it is important because, in a little while, a change occurs in the patient's ECG, the patient had a heart attack and may have occluded a saphenous graft. (N1)

Another point that deserves attention for discussion in this category is the nursing technicians' report, especially on the night shift, regarding the dimensioning of staff, since the insufficiency of employees to work in the ICU may negatively impact the care for the patient.

[...] We had cases in which it was possible to keep an exclusive employee for the patient in the postoperative period of heart surgery [...] due to lack of employees. (T1)

When there is heart surgery in the ICU under study, the institution recommends a nursing technician dedicated for this patient. However, in the night shift, there are five nursing technicians; and, if the ICU has all the beds occupied, it is not possible to follow this guideline since there is no employee reassignment to increase the number of nursing technicians in this period.

\section{DISCUSSION}

The study allowed us to identify the ICU nursing team's difficulties with patient care in the postoperative period of heart surgery. The first category of the results found highlights aspects 
related to the professional's qualification. The participants pointed out the lack of professional experience in caring for this patient as an important critical node. It is possible to understand the concern felt when dealing with this patient in the ICU, as the assistance provided must be based on complications prevention and treatment and the mitigation of intercurrences ${ }^{(5)}$. To understand the importance of professional qualification in this context, a study conducted in a hospital in Italy and another in Lebanon mapped out the individual skills nurses need to work with critically ill patients in the ICU. Some competencies listed were handling intercurrences, monitoring vital signs, recognizing signs of hemodynamic instability, and assisting patients with impaired heart function ${ }^{(16)}$.

To supply the requirement for professional experience on patient care in the postoperative of heart surgery and feel more confident, the research participants point out the need to create educational practices on the subject. In this context, it is possible to affirm that the team responsible for this patient care must participate in teaching-learning activities about the treatment in the postoperative period of heart surgery to promote safe care ${ }^{(17)}$.

In their speech, the participants noted that the participants refer to the teaching-learning strategies linked to $\mathrm{PEH}$ as qualification or training, which are related to Continuing Education. These concepts were also subject to confusion in managers' speeches in a study aiming to identify the PEH concepts they used $^{(18)}$. Therefore, it is worth highlighting that training, widely used by institutions, is not always part of an $\mathrm{PEH}$ process ${ }^{(19)}$. Training values the transmission of knowledge, inhibiting critical reflection on the needs found in daily work ${ }^{(20)}$.

Still, about the need to implement teaching-learning strategies brought by professionals, it is possible to infer, based on one of the nursing technicians' statement, that he does not feel included in the ICU work process. He is also not a protagonist of everything he carries out in his work environment since he feels obliged to participate in educational activities that are not relevant to his daily practice. In this sense, the critical nodes experienced are not the target of discussions since the training offered is punctual and fragmented; a fact also pointed out in other studies' results ${ }^{(20-21)}$. Thus, there is a necessity to conduct discussions on the difficulties faced daily so that, from them, it is possible to transform professional practice ${ }^{(19)}$.

The participants of this research also observe the importance of maintaining the continuous improvement of the educational practices for the entire nursing team, meeting PEH's assumptions, which problematize the daily work itself to build knowledge, consider professionals as reflective actors incorporate learning to the organizational routine ${ }^{(19)}$.

The second category of results found in this study presents the main challenges regarding the specific patient care in the postoperative period of heart surgery: issues related to pleural and/or mediastinal drains, vasoactive medications, invasive hemodynamic monitoring, and recognition of postoperative complications. The care provided to patients in the postoperative period of heart surgery, reported by professionals, is convergent with those of another ICU study, which showed that the leading nursing care prescribed to patients in the postoperative period of myocardial revascularization were: checking vital signs, keeping continuous monitoring, bleeding monitoring CVP checking, registering drainage output, among others ${ }^{(5)}$. Therefore, the skillful execution of procedures and qualified nursing assistance are crucial to ensure the patient's recovery in the postoperative period of heart surgery.

The first critical node discussed in this category is the care/ handling of pleural and/or mediastinal drains. Observing the output of thoracic drains is mandatory in the postoperative heart surgery period to assess whether there is excessive bleeding or blood accumulated in the mediastinal or pleural cavities ${ }^{(3-22)}$. Regarding the drainage volume, excessive bleeding is drainage greater than $3 \mathrm{ml} / \mathrm{kg} / \mathrm{h}$ in the first three postoperative hours and more than $1.5 \mathrm{ml} / \mathrm{kg} / \mathrm{h}$ after this period ${ }^{(22)}$. This situation requires attention, as there may be a need for surgical reintervention. Thus, the lack of knowledge on this aspect may delay the health team's conduct, which will worsen the patient clinical condition and delay the recovery.

As for the drainage milking interval, the participants' concern about this practice is understood since a systematic review on the subject has not found universal evidence regarding the need to manipulate those devices ${ }^{(22)}$. However, nowadays, it is recommended that the drainage milking should not be performed routinely, but only when there is a visible clot, as this procedure can increase bleeding and cause injury to nearby tissues due to the negative pressure exerted ${ }^{(22)}$.

Nursing technicians also reported little knowledge about vasoactive drugs. A study conducted in Spain applied a questionnaire to nurses in an ICU to assess medications' level of knowledge. As a result, $42.5 \%$ missed more than half of the questions, and $60 \%$ had knowledge gaps regarding noradrenaline dilution ${ }^{(23)}$. This data converges with the little knowledge that nursing technicians exposed in this study. The situation found is troublesome since care with the infusion of vasoactive drugs is essential to ensure the patient's hemodynamic stability in the postoperative period of heart surgery.

The installation and measurement of invasive MAP and CVP are also techniques that cause distress to participants. A study carried out with undergraduate nursing students in Santos, in São Paulo, whose majority was of nursing technicians, aimed at identifying the most challenging procedures to be performed in the care of critical patients: measuring CVP was the technique most remembered $^{(24)}$. This result is in line with what was presented in this study.

Regarding the invasive MAP, it is known that hemodynamic monitoring using this technique is essential for treating heart disease patients in the ICU, so the nursing team must dominate the management of this invasive system ${ }^{(25)}$. In this sense, a survey conducted in three intensive care units in the countryside of São Paulo, aiming to assess and self-evaluate nurses' knowledge on direct and indirect blood pressure measurements, pointed out limitations regarding the invasive blood pressure measurement ${ }^{(26)}$. This result is similar to what was found in the present study, as participants have reported that the measurement of invasive MAP is a critical node experienced in patient care in the postoperative period of heart surgery, as this generates concern, a fact that generates concern, as the critical patient needs strict MAP control ${ }^{(26)}$.

The recognition of the possibility of complications in the postoperative period of heart surgery and, consequently, the 
rapid detection of these intercurrences and interventions to avoid unfavorable outcomes are pointed out by the participants as the last critical node discussed in the category the challenges of nursing care in this context. Studies show that several complications may occur in the postoperative heart surgery period, such as cardiogenic shock, hemodynamic instability, hypotension, bleeding, atrial fibrillation, hyperglycemia, acute renal failure, stroke, cardiac arrest, among others ${ }^{(5,7)}$. Therefore, the participants in this study understand the importance of providing qualified care to patients after heart surgery to detect such complications early. In this sense, their speeches corroborate the thought that the nursing team should provide quality assistance based on technical-scientific knowledge, thus considering the patient's complexity and fast decision-making in clinical and surgical complications ${ }^{(3-17)}$.

The last category of this study, "The (dis)organization of work in the ICU and its impact on the nursing care for patients in the postoperative of heart surgery," pointed out limitations regarding the systematization of the nursing care to provide qualified care to that patient. The first item that deserves discussion is the tension experienced by nurses and nursing technicians at the time of the patient's admission, which can generate stress, fear, and uncertainty about the care they provide. A study conducted in two hospitals in Saudi Arabia showed that nurses working in cardiac ICUs had a higher stress level compared to those working in surgical ICUs in general ${ }^{(27)}$. Therefore, it is possible to infer that the complexity of the care to this patient profile requires quick decision-making, but with certainty, it can cause uncomfortable experiences not only for nurses but also for nursing technicians, as observed in the present study.

This research's participants miss tools that standardize care for this patient, guide nursing care, and provide information to recognize signs of complications. In this line, the protocol is considered a support method in the theoretical-practical perspective, which helps plan the care provided to achieve quality care $^{(28)}$. Thus, patient care complexity in the postoperative heart surgery period requires a defined course in carrying out care actions, considering possible complications.

Still, about this theme, the participants mention that the communication, at the time of shift change, between the CC and the ICU needs improvement. This activity's importance is emphasized, as it guides several aspects of the care that must be provided to the patient ${ }^{(29)}$. A study carried out in the Adult ICU of a teaching hospital in Goiânia, state of Goiás, pointed out gaps in information during the shift change from CC to ICU(30). Items such as the patient's age, diagnosis, surgical procedure, intercurrences, vasoactive drugs, invasive MAP, and thoracic drains were neglected or little-remembered ${ }^{(30)}$. These findings corroborate the expressions of dissatisfaction regarding the shift change observed in the participants'speeches, mainly regarding the intercurrences in the trans-operative and primary diagnosis, which influence the care in the ICU.

Another critical node found was the difficulty of meeting the institution's recommendation to appoint, in the night shift, a dedicated nursing technician for patient care in postoperative heart surgery. When comparing this institution's reality with the international context ${ }^{(16)}$ and with the Collegiate Board of Directors Resolution guidelines $N^{\circ}$. 26/2012, it is adequate for each shift, a nursing technician for every two beds ${ }^{(31)}$ for each shift. However, the specificities of patients are not considered, such as those in the postoperative period of heart surgery, which, in practice, implies work overload for the nursing team. This situation points to the need to readjust staff sizing.

Based on the discussion about the nursing team's critical nodes in the care provided to the patient in the postoperative period of heart surgery, it is possible to see that professionals recognize the existing limitations in daily practice, whether technical, institutional, or professional qualification. Those difficulties can negatively impact care and, in turn, patient safety. In a study conducted in two ICUs in southern Brazil, participants (doctors, nurses, and nursing technicians) pointed out that the implementation of protocols, the insertion of discussions about patient safety in $\mathrm{PEH}$ strategies, and the involvement of professionals and institution are measures that can be adopted to promote skills and attitudes committed to patient safety ${ }^{(32)}$.

\section{Limitations of study}

The present study shows a limitation since it was performed in only one institution. Thus, further studies on the subject are needed with the nursing team and other professionals composing the staff of other intensive care units.

\section{Contributions to the Nursing field}

The study allowed us to reflect on patient care in the postoperative period of heart surgery since it identified the nursing team's difficulties in professional practice. Moreover, the complexity of care observed in this context made us think about the need for proposals for interventions to untie the critical knots experienced by professionals in their daily practice.

\section{FINAL CONSIDERATIONS}

The study identified the critical nodes related to nursing care for the patient in the postoperative period of heart surgery, which is associated with limitations in professional qualification, poor skill and technical knowledge to provide specific care to this patient, and the (dis)organization in the ICU work, which can negatively impact on patient safety.

Given the identification of critical nodes experienced on patient care in the postoperative period of heart surgery, the participants brought suggestions for interventions to meet the demands faced in daily routine: investment in strategies related to $\mathrm{PEH}$, not only for new employees, to feel safer with the care they must provide to this ICU patient, but also for those who already work in this context, in order to strengthen their professional practice continuously; creation of instruments to guide patient care in the postoperative period of heart surgery in the ICU, such as the creation of manuals, protocols and checklists for shift changing; and provision of adequate human resources by the institution. 


\section{ERRATUM}

Article "Nursing care for patient in post operatory heart surgery in the Intensive Care Unit", with number of DOI: https://doi.org/10.1590/0034-7167-2020-0163, published in the journal Revista Brasileira de Enfermagem, 74(2): e20200163, in the title and header:

Where to read:

\section{Nursing care for patient in post operatory heart surgery in the Intensive Care Unit}

\author{
Cuidados de enfermagem ao paciente no \\ pósoperatório de cirurgia cardíaca, na \\ Unidade de Terapia Intensiva
}

Read:

\section{Nursing care for patient in postoperatory heart surgery in the Intensive Care Unit}

\section{Cuidados de enfermagem ao paciente no pós-operatório de cirurgia cardíaca, na Unidade de Terapia Intensiva}

How to quote this article, where it read:

Nursing care for patient in post operatory heart surgery in the Intensive Care Unit

Read:

Nursing care for patient in postoperatory heart surgery in the Intensive Care Unit

\section{REFERENCES}

1. Dessote CAM, Furuya RK, Rossi LA, Dantas RAS. Relation between stressors and hemodynamic instability in the postoperative period after cardiac surgery. Texto Contexto Enferm. 2018;27(3):01-09. https://doi.org/10.1590/0104-070720180004530017

2. Ministério da Saúde (BR). Secretaria da Gestão Estratégica e Participativa. Departamento de Informática do SUS (DATASUS) [Internet]. 2020[cited 2020 Mar 11]. Available from: http://tabnet.datasus.gov.br/cgi/tabcgi.exe?sih/cnv/qiuf.def

3. Branco CSPC, Pereira HO. Cuidados de enfermagem ao paciente em pós-operatório imediato de cirurgia de revascularização do miocárdio. Enferm Rev [Internet]. 2016 [cited 2019 Jul 25];19(1):72-84. Available from: http://periodicos.pucminas.br/index.php/enfermagemrevista/ article/view/11639

4. Labata C, Oliveras T, Berastegui E, Ruyra X, Romero B, Camara ML. Intermediate care unit after cardiac surgery: impact on length of stay and outcomes. Rev Esp Cardiol. 2018;71(8):638-642. https://doi.org/10.1016/j.rec.2017.10.018

5. Silva LDC, Melo MVP, Rolim ILTP, Dias RS. Intervenções de enfermagem em pacientes de unidade de terapia intensiva cardiológica de um hospital universitário submetidos à cirurgia de revascularização do miocárdio. J Manag Prim Health Care [Internet]. 2018 [cited 2019 Jan 25];9(e12):01-18. Available from: http://www.jmphc.com.br/jmphc/article/view/510/735

6. Silva LLT, Mata LRF, Silva AF, Daniel JC, Andrade AFL, Santos ETM. Cuidados de enfermagem nas complicações no pós-operatório de cirurgia de revascularização do miocárdio. Rev Baiana Enferm. 2017;31(3):e20181. https://doi.org/10.18471/rbe.v31i3.20181

7. Dordetto PR, Pinto GC, Rosa TCSC. Pacientes submetidos à cirurgia cardíaca: caracterização sociodemográfica, perfil clínico-epidemiológico e complicações. Rev Fac Cienc Med Sorocaba. 2016;18(3):144-49. https://doi.org/10.5327/Z1984-4840201625868

8. Carrias FMS, Sousa GM, Pinheiro JDS, Pereira MCC, Guimarães AEV, et al. Humanized visit in an intensive care unit: a multidisciplinary look. Tempus. 2018;11(2):103-12. https://doi.org/10.18569/tempus.v10i4.1966

9. Marshall JC, Bosco L, Adhikari NK, Connolly B, Diaz JV, Dorman T. What is an intensive care unit? a report of the task force of the World Federation of Societies of Intensive and Critical Care Medicine. J Crit Care. 2017;37:270-276. https://doi.org/10.1016/j.jcrc.2016.07.015

10. Fernandes MVB, Aliti G, Souza MN. Perfil de pacientes submetidos à cirurgia de revascularização miocárdica: implicações para o cuidado de enfermagem. Rev Eletrônica Enferm [Internet]. 2009 [cited 2019 Jul 25];11(4):993-9. Available from: https://www.fen.ufg.br/revista/v11/n4/ pdf/v11n4a25.pdf

11. Faiz T, Saeed B, Ali S, Abbas Q, Malik M. OR to ICU handoff: theory of change model for sustainable change in behavior. Asian Cardiovasc Thorac Ann. 2019;27(6):452-8. https://doi.org/10.1177/0218492319850730

12. Reis GAX, Oliveira JLC, Ferreira AMD, Vituri DW, Marcon SS, Matsuda LM. Difficulties to implement patient safety strategies: perspectives of management nurses. Rev Gaúch Enferm. 2019;40(esp):e20180366. https://doi.org/10.1590/1983-1447.2019.20180366 
13. Lacerda JT, Botelho LJ, Colussi CF. Planejamento na atenção básica [Internet]. Universidade Federal de Santa Catarina, Florianópolis, 2013[cited 2019 Jan 25]. Available from: https://unasus.ufsc.br/atencaobasica/files/2017/10/Planejamento-na-Aten\%C3\%A7\%C3\%A3oB\%C3\%A1sica-ilovepdf-compressed.pdf

14. Minayo MCS. O desafio do conhecimento: pesquisa qualitativa em saúde. 14 ed. São Paulo: Hucitec; 2014. 407p.

15. Polit DF, Beck CT. Fundamentos de pesquisa em enfermagem. 9 ed. Porto Alegre: Artmed; 2018. 456p.

16. Alfieri E, Mori M, Barbui V, Sarli L. Advanced competencies mapping of critical care nursing: a qualitative research in two Intensive Care Units. Acta Biomed. 2017;88(s3):67-74. https://doi.org/10.23750/abm.v88i3-S.6616

17. Silva WLAV, Barros ATL, Santos RD, Silva LA, Miranda LN. Cirurgias cardíacas: assistência de enfermagem a portadores de cardiopatia no período perioperatório. Cad Grad Ciênc Hum Soc Unit [Internet]. 2017 [cited 2019 Jul 30];4(2):323-36. Available from: https://periodicos.set. edu.br/index.php/fitsbiosaude/article/view/4565/2625

18. Mishima SS, Aiuba AC, Rigato AFG, Fortuna CM, Matumoto S, Ogata MN, Silva MV, Nogueira AC. Managers' perspective on continuous health education in a region of São Paulo State. Rev Esc Enferm USP. 2015;49(4):665-73. https://doi.org/10.1590/S0080-623420150000400018

19. Ministério da Saúde (BR). Secretaria de Gestão do Trabalho e da Educação na Saúde. Departamento de Gestão da Educação em Saúde. Política Nacional de Educação Permanente em Saúde [Internet]. Brasília: Ministério da Saúde; 2009 [cited 2019 Jul 31]. Available from: http:// portal.anvisa.gov.br/documents/33856/396770/Pol\%C3\%ADtica+Nacional+de+Educa\%C3\%A7\%C3\%A3o+Permanente+em+Sa\%C3\%BA de/c92db117-e170-45e7-9984-8a7cdb111faa

20. Montanha D, Peduzzi M. Permanent education in nursing: survey to identify the necessities and the expected results based on the workers conception. Rev Esc Enferm USP. 2010;44(3):597-604. https://doi.org/10.1590/S0080-62342010000300007

21. Ferreira F, Barbosa JSA, Esposti CDD, Cruz MM. Permanent Health Education in primary care: an integrative review of literature. Saúde Debate. 2019;43(120):223-39. https://doi.org/10.1590/0103-1104201912017

22. Silva LDC, Brito LL. Manipulação de drenos mediasitinais e pleurais: existe evidência científica? J Manag Prim Health Care. 2015;6(1):86-102. https://doi.org/10.14295/jmphc.v6i1.236

23. Gracia JE, Serrano RB, Garrido JF. Medication errors and drug knowledge gaps among critical-care nurses: a mixed multi-method study. BMC Health Serv Res. 2019;19(640):1-9. https://doi.org/10.1186/s12913-019-4481-7

24. Galvão ECF, Püschel VAA. Multimedia application in mobile platform for teaching the measurement of central venous pressure. Rev Esc Enferm USP [Internet]. 2012 [cited 2019 Jul 29];46(esp):107-15. Available from: http://www.scielo.br/pdf/reeusp/v46nspe/en_16.pdf

25. Langwieser N, Prechtl L, Meidert AS, Halpfelmeir A, Bradaric C, Ibrahim, T, et al. Radial artery applanation tonometry for continuous noninvasive arterial blood pressure monitoring in the cardiac intensive care unit. Clin Res Cardiol. 2015;104:518-524. https://doi. org/10.1007/s00392-015-0816-5

26. Almeida TCF, Lamas JLT. Nurses of adult intensive care unit: evaluation about direct and indirect blood pressure measurement. Rev Esc Enferm USP [Internet]. 2013 [cited 2019 Jul 29];47(2):369-76. Available from: http://www.scielo.br/pdf/reeusp/v47n2/en_14.pdf

27. Alharbi $\mathrm{H}$, Alshehry A. Perceived stress and coping strategies among ICU nurses in government tertiary hospitals in Saudi Arabia: a crosssectional study. Ann Saudi Med. 2019;39(1):48-55. https://doi.org/10.5144/0256-4947.2019.48

28. Paes GO, Mello ECP, Leite JL, Mesquita MGR, Oliveira FT, Carvalho SM. Care protocol for clients with respiratory disorder: tool for decision making in nursing. Esc Anna Nery. 2014;18(2):303-10. https://doi.org/10.5935/1414-8145.20140044

29. Corpolato RC, Montovani MF, Willig MH, Andrad, LAS, Mattei AT, Arthur JP. Standardization of the duty shift in a General Adult Intensive Care Unit. Rev Bras Enferm. 2019;72(Suppl 1):88-95. https://doi.org/10.1590/0034-7167-2017-0745

30. Bueno BRM, Moraes SS, Suzuki K, Gonçalves FAF, Barreto SASS, Gebrim CFL. Characterization of handover from the surgical center to the intensive care unit. Cogitare Enferm. 2015;20(3):512-18. https://doi.org/10.5380/ce.v20i3.40274

31. Ministério da Saúde (BR). Resolução n 26, de 11 de maio de 2012, altera a Resolução RDC n 7, de 24 de fevereiro de 2010, que dispõe sobre os requisitos mínimos para funcionamento de Unidades de Terapia Intensiva e dá outras providências[Internet]. 2012 [cited 2019 Jul 30 ]. Available from: http://bvsms.saude.gov.br/bvs/saudelegis/anvisa/2012/rdc0026_11_05_2012.html

32. Souza CS, Tomaschewski-Barlem JG, Dalmolin GL, Silva TL, Neutzling BRS, Zugno RM. Strategies for strengthening safety culture in intensive care units. Rev Enferm UERJ. 2019;27(e38670):1-7. https://doi.org/10.12957/reuerj.2019.38670 